\title{
Growth and Development of the Fetal Rhesus Monkey (Macaca mulatta). II. Total Nitrogen, Protein, Lipid, Glycogen, and Water Composition of Major Organs
}

\author{
George R. Kerr ${ }^{[31]}$, James A. Campbell, Arthur C. Helmuth, and Harry A. Waisman \\ Department of Pediatrics and The Regional Primate Research Center, University of Wisconsin, Madison, Wisconsin, USA
}

\section{Extract}

The developmental changes in the fractional nitrogen, protein, lipid, glycogen, and water content of major organs have been defined in the fetal rhesus monkey; the placenta, liver, brain, kidney, muscle, and lung were analyzed for each component at $50,75,100,125,150$, and 175 days conceptual age, and the data were compared with those of healthy adult monkeys. Each organ was found to "mature" biochemically at characteristic rates. The relative water content of each organ showed a variable decrease with advancing fetal and postnatal life. The liver demonstrated the lowest value at each age studied, and the lung showed little change in its relative water content until structural maturation and extrauterine respiratory movements occurred. The value for fetal muscle showed the greatest rate of decrease with advancing gestation: the rate of change closely paralleled that previously reported for total body water during fetal life in this species.

The relative nitrogen and protein content of all organs except the liver increased sequentially during fetal life; lung showed a marked increase in these values during late gestation and was the only organ which did not show an additional increase between birth and adult life. Muscle showed the steepest rate of increase in relative protein content during fetal life. The value for liver decreased between 75 and 100 days gestational age; thereafter little change was apparent until after 150 days, when a marked increase occurred.

The relative lipid content of each fetal organ showed a characteristic pattern of change during fetal life; muscle and placenta demonstrated low values at all ages studied. The adult value for lung was reached by the time of full-term gestation. The relative lipid content of the liver was higher than those of other organs during the first half of pregnancy; little change occurred during fetal life, but major increases were seen between 150 and 175 days conceptual age, and between birth and adult life. The relative lipid content of the brain was greater than that of all other organs at the completion of fetal life; the level increased markedly during late gestation and continued after birth.

The relative glycogen content of the kidney and brain was low at all ages studied; the lung had elevated levels early in gestation which fell with structural maturity. The value for fetal muscle rose progressively until 150 days gestational age, then fell to adult levels. Adult values for liver were reached prior to the time of full-term gestation, but a marked decrease occurred during the neonatal period. These data will 
provide control values for studies into the nutritional factors influencing fetal growth and development.

\section{Speculation}

The patterns of physical, structural, biochemical, and behavioral development of the postnatal rhesus monkey are generally comparable to those of the postnatal human infant and child; enough data now exist to indicate that many of the processes of fetal biology of these two primate species are also similar. We suggest that investigations of agents which may be of benefit or detriment to the human fetus may be conducted during pregnancy in the rhesus monkey with some assurance that the resultant data may be relevant to events which occur during pregnancy in the human.

\section{Introduction}

Abnormalities of fetal development may result in fetal death, or a lifetime of disability due to a wide variety of structural and functional disorders. A major expansion of interest in human fetal biology has occurred during recent years, but only in rare instances are normal human fetuses available for analysis. As a result, a wide variety of laboratory animals have been proposed as "models" for the definition of normal fetal biology. In many of these the processes of fetal growth and the morphology of the placenta are sufficiently different from those of higher primates to raise serious doubts concerning the applicability of many of these data to the human fetus. Fortunately, the structure of the placenta [1]; the rates of growth of fetal organs [11]; and the postnatal sequences of structural [12], biochemical [12], and behavioral [7, 8] development of a subhuman primate, Macaca mulatta, are generally comparable to those which occur in man and have been standardized enough to indicate the potential value of this species in the study of human developmental biology. As a prerequisite to investigations into the nutritional factors which influence fetal growth, this study reports the sequential changes which normally occur in the relative water, nitrogen, protein, glycogen, and lipid content of major organs during fetal life of the rhesus monkey.

\section{Materials and Methods}

\section{Procedural Methods}

Thirty-six female rhesus monkeys, the majority purchased during infancy or adolescence, were utilized only for the purpose of this study. All animals were housed in individual cages under standard conditions of light, temperature, and humidity [12] and were fed a commercial chow [28] with daily supplements of milk, vitamins, and seasonal fruit. Records were kept on menstrual bleeding, body weight, and signs of clinical health. After sexual maturation, the females were bred, and the dates of conception were accurately established [23]. Full-term gestation in this species is 168 \pm 4 days. Fifty-six single pregnancies were interrupted bs cesarean section delivery at exactly $50,75,100,125$, or 150 days gestational age; 12 additional studies were conducted at 175 days conceptual age, either at cesarean section delivery or at sacrifice of infant monkeys born at earlier dates. Surgery was conducted under local anesthesia with the female immobilized in a restraining device. Following collection of amniotic fluid and simultaneous samples of umbilical cord and maternal venous blood, the fetus and placenta were delivered, weighed, and analyzed for a variety of studies. Organ weights have been reported previously [11] and are reproduced in Table I.

The fetal lung, liver, brain, kidney, muscle, and placenta were analyzed for gross biochemical composition. All tissues were dissected clear of visible fat, peripheral nerves, and connective tissue; blotted to remove excess surface liquid; and processed within a period of $5 \mathrm{~min}$ after death. Analyses of the kidney, liver, and lung were performed on wedge sections which included both the periphery and central zone of the organs. The placental membranes were removed prior to selection of tissue for analyses. One complete cerebral hemisphere from each fetus was used for determination of its biochemical composition; a small piece of frontal lobe containing both grey and white matter was removed for evaluation of water content; then the remainder of the hemisphere was homogenized, frozen in liquid nitrogen, and stored at $-25^{\circ}$ until the other analyses were performed. Determinations of fetal muscle composition were usually performed on the tibialis anterior, gastrocnemius, and soleus muscles of the lower extremity; in the younger fetuses it was also 
Table I. Organ and body weights during fetal life of $M$. mulatta $[11]^{1}$

\begin{tabular}{|c|c|c|c|c|c|c|c|c|}
\hline $\begin{array}{l}\text { Conceptual age, } \\
\text { days }\end{array}$ & $50(6)^{2}$ & $75(10)$ & $100(7)$ & $125(9)$ & $150(9)$ & $175(8)$ & $\begin{array}{c}\text { Adult } \\
\text { males }(27)\end{array}$ & $\begin{array}{l}\text { Adult } \\
\text { females(15) }\end{array}$ \\
\hline Brain & - & $5.26 \pm 0.64$ & $18.36 \pm 1.15$ & $41.25 \pm 3.57$ & $51.85 \pm 3.04$ & $58.00 \pm 5.97$ & $87.14 \pm 12.46$ & $82.19 \pm 15.19$ \\
\hline Lung & $0.097 \pm 0.04$ & $1.32 \pm 0.20$ & $4.01 \pm 0.88$ & $6.48 \pm 1.42$ & $9.53 \pm 1.27$ & $6.29 \pm 0.99$ & $51.85 \pm 15.59$ & $51.92 \pm 14.28$ \\
\hline Liver & $0.15 \pm 0.06$ & $1.80 \pm 0.40$ & $5.84 \pm 0.69$ & $9.33 \pm 1.27$ & $14.81 \pm 1.49$ & $15.85 \pm 2.84$ & $144.89 \pm 48.63$ & $138.16 \pm 46.29$ \\
\hline Kidney & $0.017 \pm 0.01$ & $0.23 \pm 0.08$ & $1.15 \pm 0.16$ & $1.92 \pm 0.37$ & $2.37 \pm 0.37$ & $2.96 \neq 0.67$ & $24.14 \pm 6.44$ & $25.45 \pm 11.19$ \\
\hline Placenta & $21.23 \pm 6.59$ & $59.99 \pm 12.23$ & $97.27 \pm 14.66$ & $114.82 \pm 21.28$ & $165.88 \pm 33.82$ & $206.40 \pm 49.52$ & - & - \\
\hline Total body wt & $4.00 \pm 0.99$ & $43.27 \pm 3.49$ & $149.29 \pm 9.73$ & $295.30 \pm 27.00$ & $467.38 \pm 42.76$ & $544.4 \pm 101.6$ & $6186 \pm 1775$ & $5590 \pm 1760$ \\
\hline
\end{tabular}

1 Figures represent the mean value in grams \pm 1 so. Reproduced by permission of the editors of Growth.

2 Numbers in parentheses indicate the number of animals studied at each gestational age.

necessary to utilize the quadriceps extensors of the knee and the biceps of the upper extremity.

Most of the determinations of total organ water, lipid, and nitrogen were performed on the same group of 43 fetuses. Of the seven animals studied at 175 days conceptual age, four had been born by vaginal delivery at least 1 day prior to death and three were killed immediately after cesarean section delivery at that age. No obvious differences were found between the measurements obtained from these two groups, and the results were combined. The majority of the studies of glycogen composition were performed on a separate series of 25 fetuses. Each of the five animals studied at 175 days in this series had been delivered by cesarean section at least 1 day prior to death. All postnatal animals killed at 175 days conceptual age were fed a routine diet 2 hr prior to death. Six male adult animals were killed while in good health $4 \mathrm{hr}$ after a routine feeding in order to obtain comparative data.

\section{Biochemical Methods}

The relative composition of water and solid was determined by weighing pieces of organs in preweighed bottles immediately after removal from the animal. These were then desiccated to constant weight over solid $\mathrm{KOH}$. Tissues used for determination of nitrogen content were either processed immediately or frozen at $-25^{\circ}$ until analysis could be performed. Tissues were homogenized in $0.25 \mathrm{M}$ sucrose and analyzed for total nitrogen content by a modification of the method of Miller and Miller [13]. A second aliquot of the homogenized tissue was mixed with an equal volume of $10 \%$ trichloroacetic acid and centrifuged, and the supernatant fluid and washings were analyzed to determine the nonprotein nitrogen value. The precipitate was resuspended in $0.1 \mathrm{~N} \mathrm{NaOH}$ and analyzed for the protein nitrogen value. The latter figure, multiplied by 6.25 [15], was used to define the total protein content of the tissues.

The total lipid content of representative samples of each organ was determined by a modification of the method of Rouser et al. [17] using three extractions with $10 \mathrm{ml}$ chloroform-methanol $(2: 1) / \mathrm{g}$ tissue following the initial extraction with $20 \mathrm{ml} / \mathrm{g}$ tissue. All solvents were ACS grade and redistilled. The combined extractions were evaporated, resuspended in the extraction solution, filtered, and evaporated to constant weight over solid $\mathrm{KOH}$ in a vacuum desiccator flushed with nitrogen. The final weight of the dried extracts was used to determine the total lipid content of the tissue. The total glycogen composition of tissue was determined by quantifying the glucose content after precipitation and hydrolysis of the glycogen [5]. Duplicate analyses were routinely performed on three representative samples of each tissue, and the mean value was used to determine the total glycogen content of the organ.

\section{Results}

The biochemical composition of the organs is presented in Tables II through $\mathrm{V}$. The results are expressed as the mean value $\pm 1 \mathrm{sD}$; unless otherwise indicated (by a number in parentheses), the data represent five studies at each age.

The relative water content of all organs decreased during gestation and to varying extents during postnatal life (Table II); each organ showed a characteristic pattern of change. The water composition of the lung, kidney, muscle, brain, and placenta accounted for 85-90\% of the total organ weights at 75 days gestational age; by the time of birth these values had decreased to $76-82 \%$. The relative water content of the liver was considerably less than that of other organs at each gestational age, and the value for adult liver was reached by the time of birth. The value for lung showed little change until a marked decrease occurred between 150 and 175 days, presumably associated with extrauterine respiration. This decrease was seen in lungs of infant monkeys born at least 1 day prior to death and also in those killed immediately after cesarean section delivery. Most of the latter animals took 
Table II. Total water of fetal organs ${ }^{2}$

\begin{tabular}{|c|c|c|c|c|c|c|c|}
\hline $\begin{array}{l}\text { Conceptual age, } \\
\text { days }\end{array}$ & 50 & 75 & 100 & 125 & 150 & 175 & Adult \\
\hline Brain & - & $88.83 \pm 0.50$ & $\begin{array}{c}89.64 \pm 0.96 \\
(6)\end{array}$ & $\begin{array}{c}89.08 \pm 0.47 \\
(6)\end{array}$ & $\begin{array}{c}86.13 \pm 0.44 \\
(8)\end{array}$ & $\begin{array}{c}82.82 \pm 2.33 \\
(6)\end{array}$ & $76.50 \pm 0.64$ \\
\hline Lung & - & $\begin{array}{c}86.39 \pm 1.29 \\
(6)\end{array}$ & $85.75 \pm 2.16$ & $87.26 \pm 1.14$ & $88.05 \pm 1.20$ & $\begin{array}{c}82.32 \pm 3.32 \\
(6)\end{array}$ & $\begin{array}{c}79.43 \pm \\
(6)\end{array}$ \\
\hline Liver & - & $76.66 \pm 1.00$ & $\begin{array}{c}74.22 \pm 1.71 \\
(6)\end{array}$ & $\begin{array}{c}72.20 \pm 1.11 \\
(6)\end{array}$ & $\begin{array}{c}70.62 \pm 1.36 \\
(8)\end{array}$ & $\begin{array}{c}71.62 \pm 2.42 \\
(7)\end{array}$ & $\begin{array}{c}70.32 \pm 1.52 \\
(6)\end{array}$ \\
\hline Muscle & - & $88.42 \pm 0.56$ & $\begin{array}{c}84.04 \pm 0.90 \\
(6)\end{array}$ & $\begin{array}{c}80.84 \pm 0.79 \\
(6)\end{array}$ & $\begin{array}{c}77.50 \pm 1.37 \\
(8)\end{array}$ & $\begin{array}{c}77.79 \pm 1.15 \\
(7)\end{array}$ & $\begin{array}{c}76.12 \pm 0.97 \\
(6)\end{array}$ \\
\hline Kidney & - & $\begin{array}{c}85.89 \pm 1.93 \\
\text { (3) }\end{array}$ & $84.61 \pm 1.59$ & $\begin{array}{c}83.94 \pm 0.68 \\
(6)\end{array}$ & $\begin{array}{c}81.39 \pm 1.60 \\
(6)\end{array}$ & $\begin{array}{c}80.94 \pm 1.58 \\
(7)\end{array}$ & $\begin{array}{c}76.84 \pm 2.30 \\
(6)\end{array}$ \\
\hline Placenta & $\begin{array}{c}88.86 \pm 0.91 \\
(2)\end{array}$ & $\begin{array}{c}85.13 \pm 0.78 \\
(6)\end{array}$ & $\begin{array}{c}82.87 \pm 0.62 \\
(6)\end{array}$ & $\begin{array}{c}83.26 \pm 0.77 \\
(6)\end{array}$ & $\begin{array}{c}82.18 \pm 0.75 \\
(8)\end{array}$ & $\begin{array}{c}80.15 \pm 1.56 \\
(2)\end{array}$ & - \\
\hline \multicolumn{8}{|c|}{${ }^{1}$ Mean percentage of total organ weight $\pm 1 \mathrm{sD}$. Unless indicated by a number in parentheses, data represent five studies. } \\
\hline $\begin{array}{l}\text { Conceptual age, } \\
\text { days }\end{array}$ & 50 & 75 & 100 & 125 & 150 & 175 & Adult \\
\hline \multicolumn{8}{|l|}{ Brain } \\
\hline $\mathrm{TN}$ & 一 & $1.08 \pm 0.07$ & $0.97 \pm 0.04$ & $1.03 \pm 0.07$ & $1.26 \pm 0.06$ & $1.52 \pm 0.15$ & $1.82 \pm 0.15$ \\
\hline NPN & - & $0.21 \pm 0.01$ & $0.17 \pm 0.04$ & $0.21 \pm 0.02$ & $0.21 \pm 0.02$ & $0.24 \pm 0.03$ & $0.25 \pm 0.02$ \\
\hline $\mathrm{PN}$ & 一 & $0.89 \pm 0.05$ & $0.84 \pm 0.08$ & $0.91 \pm 0.07$ & $1.09 \pm 0.12$ & $1.33 \pm 0.13$ & $1.53 \pm 0.10$ \\
\hline $\mathrm{TP}$ & - & $5.61 \pm 0.34$ & $5.23 \pm 0.52$ & $5.68 \pm 0.40$ & $6.82 \pm 0.73$ & $8.30 \pm 0.80$ & $9.56 \pm 0.63$ \\
\hline \multicolumn{8}{|l|}{ Lung } \\
\hline TN & - & $1.07 \pm 0.09$ & $1.38 \pm 0.07$ & $1.50 \pm 0.18$ & $1.32 \pm 0.21$ & $2.13 \pm 0.37$ & $2.55 \pm 0.46$ \\
\hline NPN & - & $0.21 \pm 0.05$ & $0.24 \pm 0.06$ & $0.19 \pm 0.01$ & $0.16 \pm 0.02$ & $0.24 \pm 0.04$ & $0.31 \pm 0.10$ \\
\hline PN & - & $1.01 \pm 0.07$ & $1.22 \pm 0.04$ & $1.35 \pm 0.10$ & $1.13 \pm 0.17$ & $2.10 \pm 0.30$ & $2.18 \pm 0.14$ \\
\hline $\mathrm{TP}$ & 一 & $6.31 \pm 0.41$ & $7.64 \pm 0.16$ & $8.45 \pm 0.60$ & $7.05 \pm 1.05$ & $13.14 \pm 1.87$ & $13.64 \pm 0.91$ \\
\hline \multicolumn{8}{|l|}{ Liver } \\
\hline $\mathrm{TN}$ & 一 & $2.63 \pm 0.16$ & $2.40 \pm 0.11$ & $2.11 \pm 0.13$ & $2.00 \pm 0.10$ & $2.55 \pm 0.21$ & $3.16 \pm 0.17$ \\
\hline NPN & - & $0.35 \pm 0.09$ & $0.33 \pm 0.02$ & $0.31 \pm 0.02$ & $0.33 \pm 0.05$ & $0.40 \pm 0.07$ & $0.35 \pm 0.04$ \\
\hline PN & - & $2.42 \pm 0.07$ & $1.95 \pm 0.11$ & $1.95 \pm 0.10$ & $1.84 \pm 0.06$ & $2.27 \pm 0.26$ & $2.75 \pm 0.11$ \\
\hline $\mathrm{TP}$ & 一 & $15.14 \pm 0.46$ & $12.21 \pm 0.69$ & $12.22 \pm 0.60$ & $11.48 \pm 0.42$ & $14.22 \pm 1.62$ & $17.18 \pm 0.68$ \\
\hline \multicolumn{8}{|l|}{ Muscle } \\
\hline $\mathrm{TN}$ & - & $1.29 \pm 0.03$ & $1.42 \pm 0.24$ & $1.98 \pm 0.44$ & $2.39 \pm 0.45$ & $2.72 \pm 0.12$ & $2.93 \pm 0.22$ \\
\hline NPN & - & $0.28 \pm 0.03$ & $0.24 \pm 0.02$ & $0.28 \pm 0.03$ & $0.31 \pm 0.04$ & $0.31 \pm 0.07$ & $0.48 \pm 0.06$ \\
\hline $\mathrm{PN}$ & - & $1.13 \pm 0.08$ & $1.30 \pm 0.15$ & $1.71 \pm 0.29$ & $2.14 \pm 0.31$ & $2.67 \pm 0.17$ & $2.89 \pm 0.26$ \\
\hline $\mathrm{TP}$ & 一 & $7.07 \pm 0.53$ & $8.11 \pm 0.92$ & $10.72 \pm 1.78$ & $13.39 \pm 1.92$ & $16.69 \pm 1.10$ & $18.04 \pm 1.62$ \\
\hline \multicolumn{8}{|l|}{ Kidney } \\
\hline $\mathrm{TN}$ & - & $1.52 \pm 0.10$ & $1.65 \pm 0.10$ & $2.01 \pm 0.14$ & $2.21 \pm 0.11$ & $2.39 \pm 0.20$ & $2.57 \pm 0.26$ \\
\hline NPN & 一 & $0.35 \pm 0.08$ & $0.37 \pm 0.10$ & $0.36 \pm 0.10$ & $0.32 \pm 0.08$ & $0.33 \pm 0.07$ & $0.40 \pm 0.06$ \\
\hline PN & - & $1.19 \pm 0.14$ & $1.47 \pm 0.09$ & $1.78 \pm 0.13$ & $1.92 \pm 0.18$ & $2.05 \pm 0.13$ & $2.32 \pm 0.20$ \\
\hline $\mathrm{TP}$ & - & $7.45 \pm 0.87$ & $9.17 \pm 0.58$ & $11.14 \pm 0.79$ & $12.05 \pm 1.13$ & $12.80 \pm 0.81$ & $14.52 \pm 1.22$ \\
\hline \multicolumn{8}{|l|}{ Placenta } \\
\hline $\mathrm{TN}$ & $1.69 \pm 0.08$ & $1.73 \pm 0.08$ & $1.90 \pm 0.09$ & $2.05 \pm 0.27$ & $2.13 \pm 0.19$ & $2.49(1)$ & 一 \\
\hline NPN & $0.26 \pm 0.04$ & $0.27 \pm 0.03$ & $0.26 \pm 0.07$ & $0.27 \pm 0.06$ & $0.28 \pm 0.04$ & 0.28 & - \\
\hline $\mathrm{PN}$ & $1.41 \pm 0.11$ & $1.54 \pm 0.15$ & $1.73 \pm 0.13$ & $1.78 \pm 0.19$ & $1.81 \pm 0.13$ & 2.33 & 一 \\
\hline $\mathrm{TP}$ & $8.84 \pm 0.70$ & $9.63 \pm 0.94$ & $10.83 \pm 0.84$ & $11.12 \pm 1.19$ & $11.31 \pm 0.78$ & 14.56 & - \\
\hline
\end{tabular}

${ }^{1}$ Mean percentage of total organ weight $\pm 1 \mathrm{sD}$. Abbreviations used: TN: total nitrogen; NPN: nonprotein nitrogen; PN: protein nitrogen; TP: total protein (figure derived by protein nitrogen $\times 6.25$ ) [23]. Unless indicated by a number in parentheses, data represent five studies.

several breaths during the momentary interval between delivery and death. The kidney showed a progressive reduction in relative water content throughout fetal and postnatal life; that of the placenta decreased notably only during the first half of pregnancy. Muscle showed the most rapid decrease in relative water content during fetal life, and adult levels were approximated by 150 days gestational age. 
Table IV. Total lipid content of fetal organs ${ }^{1}$

\begin{tabular}{|c|c|c|c|c|c|c|c|c|}
\hline $\begin{array}{l}\text { Conceptual age, } \\
\text { days }\end{array}$ & 50 & & 75 & 100 & 125 & 150 & 175 & Adult \\
\hline Brain & - & 3.17 & $\begin{array}{l} \pm 0.53 \\
(8)\end{array}$ & $3.18 \pm 0.19$ & $\begin{array}{c}3.56 \pm 0.29 \\
(6)\end{array}$ & $\begin{array}{c}4.48 \pm 0.31 \\
\text { (8) }\end{array}$ & $6.08 \underset{(6)}{ \pm} 0.19$ & $11.46 \pm 0.84$ \\
\hline Lung & - & 1.75 & \pm 0.11 & $1.91 \pm 0.17$ & $1.94 \pm 0.23$ & $2.35 \pm 0.30$ & $3.98 \pm 0.85$ & $3.85 \pm 0.63$ \\
\hline Liver & - & 4.28 & $\begin{array}{l} \pm 0.03 \\
(6)\end{array}$ & $4.66 \pm 0.53$ & $\begin{array}{c}4.06 \pm 0.30 \\
(6)\end{array}$ & $4.26 \pm 0.30$ & $5.28 \pm 1.52$ & $\begin{array}{c}8.13 \pm 0.17 \\
(6)\end{array}$ \\
\hline Muscle & - & 1.71 & \pm 0.25 & $2.06 \underset{(4)}{ \pm} 0.29$ & $2.30 \pm 0.38$ & $2.43 \pm 0.43$ & $2.56 \pm 0.47$ & $\begin{array}{c}2.92 \pm 0.64 \\
(6)\end{array}$ \\
\hline Kidney & - & & 一 & $2.38 \underset{(4)}{ \pm} 0.29$ & $3.34 \pm 0.89$ & $4.03 \pm 0.70$ & $4.38 \pm 0.88$ & $5.61 \pm 1.16$ \\
\hline Placenta & $\begin{array}{c}2.52 \pm 0.31 \\
\text { (3) }\end{array}$ & 2.56 & \pm 0.31 & $2.93 \pm 0.44$ & $2.72 \pm 0.23$ & $\begin{array}{c}2.94 \pm 0.23 \\
(6)\end{array}$ & $\begin{array}{c}2.85(1) \\
\text { (1) }\end{array}$ & 一 \\
\hline
\end{tabular}

${ }^{1}$ Mean percentage of total organ weight $\pm 1 \mathrm{sD}$. Unless indicated by a number in parentheses, data represent five studies.

Table $V$. Total glycogen content of fetal organs ${ }^{1}$

\begin{tabular}{lccccccc}
\hline $\begin{array}{l}\text { Conceptual age, } \\
\text { days }\end{array}$ & 50 & 75 & 100 & 125 & 150 & $175^{2}$ & Adult \\
\hline Brain & - & $0.028 \pm 0.036$ & $0.025 \pm 0.004$ & $0.011 \pm 0.012(6)$ & $0.025 \pm 0.005$ & $0.015 \pm 0.004(4)$ & $0.016 \pm 0.001(4)$ \\
Lung & - & $2.63 \pm 0.49$ & $2.66 \pm 0.54$ & $0.96 \pm 0.34$ & $0.51 \pm 0.08$ & $0.23 \pm 0.10$ & $0.07 \pm 0.03(4)$ \\
Liver & - & $1.48 \pm 0.84$ & $3.92 \pm 1.03$ & $6.94 \pm 1.23(6)$ & $8.19 \pm 1.44(6)$ & $4.84 \pm 2.13$ & $10.11 \pm 2.70(4)$ \\
Muscle & - & $0.78 \pm 0.30$ & $1.34 \pm 0.36$ & $1.94 \pm 0.49(6)$ & $2.77 \pm 0.38(6)$ & $0.35 \pm 0.21$ & $0.74 \pm 0.30(4)$ \\
Kidney & - & $0.090 \pm 0.084$ & $0.074 \pm 0.030$ & $0.070 \pm 0.038(6)$ & $0.065 \pm 0.021$ & $0.040 \pm 0.023$ & $0.024 \pm 0.022(4)$ \\
Placenta & - & $0.141 \pm 0.108$ & $0.111 \pm 0.060$ & $0.033 \pm 0.035(6)$ & $0.090 \pm 0.054(6)$ & - & -
\end{tabular}

${ }^{1}$ Mean percentage of total organ weight $\pm 1 \mathrm{sD}$. Unless indicated by a number in parentheses, data represent five studies.

${ }^{2}$ All animals studied at 175 days conceptual age were born by cesarean section performed at least 1 day prior to death.

The relative nitrogen content of all organs except the liver tended to increase sequentially during fetal life and continued to varying degrees after birth (Table III). The value for brain did not show a notable increase until after 125 days gestational age. Thereafter, a progressive rise occurred during the remainder of fetal life, and an additional increase was seen in the brain of adult animals. The relative nitrogen content of lung rose sequentially during fetal life except for an apparent drop in 150-day-old animals. A marked increase to adult values occurred between 150 and 175 days conceptual age. Of all organs studied, muscle showed the steepest rate of increase in its relative nitrogen content during fetal life; values for adult muscle were nearly reached by the time of birth. The liver demonstrated a different pattern of change from that of other organs; a notable decrease occurred between 75 and 100 days conceptual age, and little change was noted thereafter until a marked increase occurred between 150 and 175 days conceptual age. A similar increase was seen between the times of birth and adult life.

Nonprotein nitrogen accounted for between 0.2 and $0.4 \%$ of the total weight of most organs: a consistent pattern of change was not seen in the relative nonpro- tein nitrogen fraction of any organ, and the changes in total organ nitrogen with increasing age were due almost entirely to changes in their relative content of protein.

The relative lipid content of muscle and kidney showed sequential increases at each successive fetal age studied (Table IV). Placental values did not change notably throughout gestation. The lung showed low levels during early fetal life, then a rapid rise to adult values around the time of full-term gestation. The relative lipid content of liver was greater than that of other organs during early fetal life, but a change in value was not seen until between 150 and 175 days conceptual age when an apparent increase occurred; the liver of adult animals showed a more impressive rise in relative lipid content. The brain had the highest relative content of lipid of all adult organs; the major increase in this value occurred during postnatal life.

The relative glycogen contents of the kidney, placenta, and brain were lower than those of other organs at all ages studied (Table V). A trend toward decreasing values with advancing age was noted for all organs except muscle and liver. This trend was most apparent in the lung, with elevated levels present early in fetal 
life and a marked decrease occurring after 100 days gestational age with the maturation of respiratory epithelium. The relative glycogen content of fetal muscle rose progressively at successive fetal ages reaching a level several times greater than that of adult muscle by 150 days of gestation; a marked fall to adult levels occurred thereafter. A rapid increase in the relative glycogen content of the liver also occurred progressively in fetal life. Adult values were reached by 150 days gestation, although a decrease occurred in the 175-day tissues which were obtained from infant monkeys born at least $l$ day prior to death.

\section{Discussion}

In order to identify those agents which may be harmful or beneficial to the human fetus, it is first necessary to define the limits of "normal" fetal growth and development. The full achievement of this goal in human fetuses will probably always be limited by moral and procedural considerations, and concepts of human fetal biology will be those which appear logical on the basis of studies in experimental animals. Although many species have been investigated to obtain data on normal fetal development, it seems reasonable that "higher" primates probably provide a closer counterpart to the total biology of the human than other species; the sequential changes in several aspects of normal development during fetal and perinatal life of the rhesus monkey have been described previously [9-12].

Studies of body composition were initiated about 100 years ago [25]; during recent years these have been extended by the development of new investigative techniques [16] and new concepts of the processes of cellular growth [26]. A concept of major importance was formulated by Moulton in 1923, when he defined the "age of chemical maturity" in several species [14]. These data indicated that, with the exception of body fat, major changes in the relative composition of the body occurred only during fetal life or childhood. Although the total body content of various nutrients increased with increasing size, most of the studies on body composition have shown a gradual reduction in the relative content of water with advancing fetal age, and corresponding increases in the relative content of protein and fat $[16,19,24]$.

The few studies which have investigated the relative water composition of individual organs have shown a decrease with advancing gestation [24], but the histological appearance of fetal tissues suggests that marked differences must exist in the relative water content of different organs. Behrman et al. [2] reported that the changes in the relative water content of the liver of the fetal rhesus monkey paralleled, but at a much lower level, the changes which occurred in total body water. The present study confirms their data and presents sequential data on the changes which occur in several other organs with advancing gestation. The only organ which showed a decrease in relative water content which was comparable with the changes in total body water reported by Behrman et al. [2] was fetal muscle. As muscle reportedly accounts for about $25 \%$ of the total body mass of the newborn [24], this would suggest that the relative decrease in total body water which occurs during fetal life primarily reflects the growth in mass of fetal muscle.

The rate of protein synthesis in fetal organs is generally higher than that seen in adult tissues $[18,27]$. As fetal organs mature functionally and structurally at differing rates, differences in their total nitrogen and protein content might be anticipated. With the exception of the liver, all organs in the fetal rhesus monkey showed a progressive increase in relative nitrogen composition; in all cases, this increase reflected a corresponding increase in protein content. These data suggest a more rapid pattern of maturation of muscle in this species than that observed in the human fetus [24]; such a discrepancy should not be unexpected, however, as newborn monkeys are capable of greater muscular activity and coordination than human newborns. The observation that the relative protein content of the liver did not increase with advancing gestation is surprising because of the known high rate of protein synthesis in that organ [27]. With the exception of muscle and liver, the changes in the relative protein content of those organs studied are generally comparable to those reported in the human [24, 25].

Changes in the lipid content of specific fetal organs have not been studied extensively except for neural tissues [22]; major species-specific differences in brain growth and composition have been described [6]. With the exception of the placenta, the relative lipid content of all organs studied in the fetal rhesus monkey showed a variable increase with advancing gestation. No organ reflected the change in total body lipid which occurs during fetal life of the human primate, however. This difference may be species-specific; the major amount of fat in the human newborn is in the form of subcutaneous and "depot" fat, essential for thermostability and the maintenance of energy in the fasting neonate. Only minimal deposits of subcuta- 
neous fat can be found in the normal newborn rhesus monkey.

Tissues demonstrating the highest relative glycogen content early in gestation are the fetal lung, liver, and heart; the fetal liver and striated muscle have the highest levels during later fetal life [4, 20]. The relative glycogen content of muscle rises rapidly until shortly before full-term pregnancy, then falls to adult levels $[3,20]$; that of the liver also rises rapidly during late pregnancy, then falls transiently after birth as these stores are depleted for energy needs. The lung shows a unique pattern of change in glycogen content; early in gestation the bronchial epithelium creates a "glandlike" appearance [21]. The "acini" of this tissue are virtually packed with glycogen. With structural maturation, the glycogen content of the lung decreases markedly [Fig. 1]. The changes in glycogen content of fetal muscle reported in the present study are similar to those previously described by Shelley [20] and more recently by Bocek et al. [3]. The relative glycogen content of the fetal liver and lung are also similar to those reported by Shelley [20]. The wide range of values found in different parts of the same organ were intriguing. This was most apparent in the liver, where threefold differences were not uncommon between different areas. Similar, but less remarkable differences were seen in each of the other organs studied. An explanation for these differences is not currently available; they are presumably related to regional cellular metabolic processes.

Studies of body and organ composition are of limited value in defining the functioning maturity of organs; although changes predictably occur during phases of normal growth, these only reflect the net activity of a large number of structural and functional biochemical compounds, each of which is deserving of study in its own right. The total lipid content of tissues can be further defined into the constituent lipids and lipoproteins; the value for total water can be extended into its anatomical position, the rates of transport across cell membranes, and the relation of this movement to the presence of specific ions and proteins with osmotic activity. And the total protein value can be ascribed to an increasing number of individual proteins, each with its own "half-life" and functional role. Additional studies involving maturation of specific fetal proteins and complex lipids are currently in progress; but even the gross values reported here can be of service in determining the normal patterns of change and indicating the times in fetal life at which
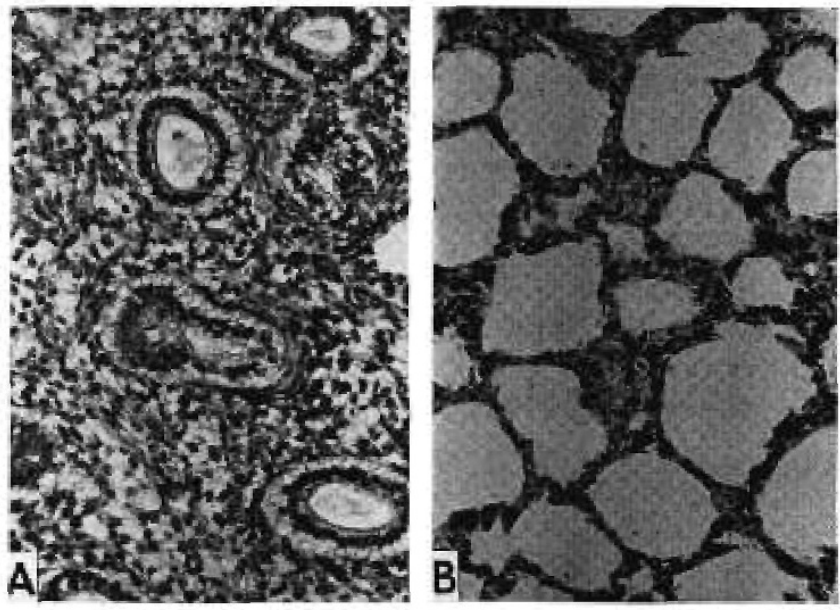

Fig. 1. Structural development of the lung during fetal life of the rhesus monkey. A: 50 days. B: 175 days conceptual age. The 175-day specimen is from an animal delivered 2 days prior to death. Hematoxylin and eosin. The bronchial epithelium seen in the 50-day tissue contains a large amount of glycogen as indicated by reaction with the periodic acid-Schiff reagent.

maximal changes occur, and which need to be studied in greater detail.

The potential for defining the normal biology of the human fetus is obviously limited: except in unusual circumstances, the human fetal tissues which are available for analyses are derived from abortions, miscarriages, stillborn, or prematurely born infants. These concerns are compounded by uncertainty of the gestational age, maternal health and nutrition, and many other variables. The species utilized in the current study presents obvious advantages in that the tissues are from "normal" primate pregnancies, can be obtained at exact gestational ages, and, as they can be processed for analysis within minutes after scheduled cesarean section delivery, can be assumed to represent the normal chemical state of gestation. While recognizing the taxonomic differences between human and subhuman primates, many similarities between the human and $M$. mulatta fetus are also apparent. These suggest that additional studies defining the normal mechanisms of fetal growth, when performed in this species, may provide data pertinent to the processes of growth and development which occur but cannot be investigated in the human fetus.

\section{Conclusion}

Events which occur early in life have been reported to permanently influence subsequent physical growth and behavioral development. In order to identify factors 
which can be of benefit or detriment to the human fetus or the prematurely born human infant, it is first necessary to define normal fetal growth and development. As such studies are rarely possible in normal human pregnancies, other species must be utilized for the definition of normal fetal biology in the hope that the resulting data may reflect the events which occur in the human fetus. As a prerequisite to studies of the nutritional factors affecting growth and development of the fetal primate, this study has investigated the sequential changes which occur in the total and relative content of water, lipid, nitrogen, protein, and glycogen of several organs during normal fetal development of the rhesus monkey.

\section{References and Notes}

1. Assali, N. S., AND Morris, J. A.: Maternal and fetal circulations and their interrelationships. Obstet. Gynecol. Surv., 19: 923 (1964).

2. Behrman, R. E., Seeds, A. E., JR., Battaglia, F. C., Helleger, A. E., AND Bruns, P. D.: The normal changes in mass and water content in fetal rhesus monkey and placenta throughout gestation. J. Pediat., 65: 38 (1964).

3. BoceK, R. M., Basinger, G. M., AND Beatty, C. H.: Glycogen synthetase, phosphorylase, and glycogen content of developing rhesus muscle. Pediat. Res., 3: 525 (1969).

4. Capkova, A., AND JiRAseK, J. E.: Glycogen reserves in organs of human foetuses in the first half of pregnancy. Biol. Neonat., 13: 129 (1968.)

5. Consolazio, G. F., and Iacono, J. M.: Carbohydrates. In: A. A. Albanese: Newer Methods of Nutritional Biochemistry, Chapt. 8, p. 200 (Academic Press, New York, 1963).

6. Davison, A. N., AND Dobbing, J.: Myelination as a vulnerable period in brain development. Brit. Med. Bull., 22: 40 (1966).

7. HarLow, H. F.: The development of learning in the rhesus monkey. Amer. Sci., 47: 459 (1959).

8. Harlow, M. K., aNd Harlow, H. F.: Affection in primates. Discovery, 27: 11 (1966)

9. KeRR, G. R.: The free amino acids of serum during development of Macaca mulatta. II. During pregnancy and fetal life. Pediat. Res., 2: 493 (1968).

10. KeRR, G. R., AND KenNAN, A. L.: The free amino acids of amniotic fluid during pregnancy of the rhesus monkey. Amer. J. Obstet. Gynecol., 105: 363 (1969).

11. Kerr, G. R., Kennan, A. L., Waisman, H. A., and Allen, J. R.: Growth and development of the fetal rhesus monkey. I. Physical growth. Growth, 33: 201 (1969).

12. KerR, G. R., Scheffler, G., AND Waisman, H. A.: Growth and development of infant $M$. mulatta fed a standardized diet. Growth, 33: 185 (1969).

13. Miller, G. L., AND Miller, E. E.: Determination of nitrogen in biological materials. Anal. Chem., 20: 481 (1948).

14. Moulton, C. R.: Age and chemical development in mammals. J. Biol. Chem., 57: 79 (1923).
15. Munro, H. N.: An introduction to nutritional aspects of protein metabolism. In: H. N. Munro and J. B. Allison: Mammalian Protein Metabolism, Vol. 2, p. 3 (Academic Press, New York, 1964).

16. OWen, G. M., ANd BRozeK, J.: Influence of age, sex and nutrition on body composition during childhood and adolescence. In: F. Falkner: Human Development, Chapt. 9, p. 222 (W. B. Saunders, Philadelphia, 1966).

17. Rouser, G., Kritchevsky, G., Heller, D., and Lieber, E.: Lipid composition of beef brain, beef liver, and the sea anemone: Two approaches to quantitative fractionation of complex lipid mixtures. J. Amer. Oil Chem. Soc., 40: 425 (1963).

18. Schain, R. J., Carver, M. J., and Copenhaver, J. H.: Postnatal changes in protein metabolism of brain. I. Studies in newborn miniature pigs at varying conceptual ages. Pediat. Res., 3: 135 (1969).

19. Seeds, A. E., JR.: Water metabolism of the fetus. Amer. J. Obstet. Gynecol., 92: 727 (1965).

20. SHeLley, H. J.: Carbohydrate reserves and their changes at birth and in anoxia. Brit. Med. Bull., 17: 137 (1961).

21. Sorokin, S., Padykula, H. A., ANd Herman, E.: Quantitative histochemical patterns in developing mammalian lungs. Develop. Biol., 1: 125 (1959).

22. SVENARRHolm, L.: The distribution of lipids in the human nervous system. I. Analytical procedure. Lipids of foetal and newborn brain. J. Neurochem., 11: 839 (1964).

23. VAN WAGENEN, G.: Mating in relation to pregnancy in the monkey. Yale J. Biol. Med., 17: 745 (1945).

24. Widnowson, E. M.: Growth and composition of the fetus and newborn. In: N. S. Assali: Biology of Gestation, Vol. 2, p. 1 (Academic Press, New York, 1968).

25. Widdowson, E. M., AND Dickerson, J. W. T.: Chemical composition of the body. In: C. L. Comar and F. Bronner: Mineral Metabolism, Vol. 2, Part A, p. 1 (Academic Press, New York, 1964).

26. WINICK, M., AND NoBle, A.: Quantitative changes in DNA, RNA and protein during prenatal and postnatal growth in the rat. Develop. Biol., 12: 451 (1965).

27. Zamecnik, P. C., Frantz, I. D., JR., Loftsfield, R. B., and STEPHENSON, M. L.: Incorporation in vitro of radioactive carbon from carboxyl-labeled DL-alanine and glycine into proteins of normal and malignant rat livers. J. Biol. Chem., 175: 229 (1948).

28. Purina Monkey Chow, Ralston Purina Company, St. Louis, Mo.

29. The assistance of Dr. James Allen and Mr. Guenther Scheffler in performing the surgical procedures is gratefully acknowledged.

30. Supported in part by National Institutes of Health Grant no. FR00167 to the Wisconsin Regional Primate Center.

31. Requests for reprints should be addressed to: George $R$. Kerr, M.D., University of Wisconsin, Regional Primate Research Center, 1223 Capitol Court, Madison, Wisconsin 53706 (USA).

32. Accepted for publication April 13, 1970. 